\title{
Architecture as a Science: Boundary Work and the Demarcation of Design Knowledge from Research
}

\author{
Monika Kurath
}

Recent STS literature has described a trend of academisation in higher education and universities in which administrative bodies and formalised practices like evaluations have gained increased influence. This article discusses the impact of such trends on the discipline of architecture, focusing on the strains and boundaries that architectural faculties face in their research and teaching practice. Specifically, the development of design knowledge from individual and multiple theoretical and methodological approaches, the tight connection with tacit knowledge forms, as well as the use of non-formalised tenure and peer-review indicate on-going processes of boundary work (Gieryn, 1983), where external disciplines evaluate architectural knowledge production and demarcate it from their own research approaches. Due to the increased meaning of evaluations, such boundary work plays an increasing role in framing the form and content of design research. In this respect, architectural research becomes a matter of negotiation that not only involves architecture, but also traditional research disciplines as well as the added restrictions of interdisciplinary and administrative bodies.

Keywords: design research, boundary work, economisation of universities, higher education, epistemic culture

\section{Boundary Work, Academisation and Epistemic Cultures}

Architectural design research depends on intuition, ideas, ideology and individual personalities who create new things that imprint the built environment. Additionally, it engages arts and the humanities. Architectural design combines pure and applied research at almost every step. (Excerpt from an evaluation report of a Swiss architecture department, 10 January 2013)
The above-mentioned quotation illustrates an example of boundary work (Gieryn, 1983), where an external evaluation committee has been involved in framing architectural design knowledge as research. The boundaries are drawn in several respects and are concerned with the content of the design practice by referring to the basis of architectural work as intuition, tacit knowledge and individuality. Further boundaries are drawn on a formal level, by identifying the disciplinary rooting of architecture in both the arts and the 
humanities and by a twofold location of its research in 'pure' and in 'applied' research.

Gieryn (1983) uses the term boundary work for describing the practice of demarcating science from other knowledge production activities. He shows that scientists have an interest in distinguishing their field specific knowledge production forms from external ones for achieving professional goals like the acquisition of intellectual authority, career opportunities and the protection of the 'autonomy' of scientific research from external influence (Gieryn, 1983). In showing that these boundaries are flexible, drawn and redrawn according to the respective scientific interests, (Gieryn, 1999) shows that the boundaries are not only socially and culturally constructed, but also science itself.

Using Gieryn's (1983) concept, the boundary work emerging in the transformation of architecture into a research discipline in the Swiss higher education system is analysed. This paper identifies the reason for this boundary work in trends described in recent STS literature towards the economisation of universities and an externally imposed process of establishing new science policy steering and management structures (Weingart, 2001; Schimank, 2008). The literature describes these strategies as subsumed under notions such as 'new public management of universities' (Schimank 2005), 'new governance of science' (e.g. Braun \& Merrien, 1999; Felt \& Fochler, 2010), 'managerial revolution' (Maasen \& Weingart, 2006: 20) and a harmonisation of higher education systems.

One of the drivers of this larger process is the European Bologna Reform, which has led to a vast top-down-enacted reformation of higher education and organisational structures of universities in a majority of European countries (Maesse, 2010). The reform has not only contributed to more formalised study program structures and standard administrative practices like auditing and evaluation of research and teaching (Schultheis et al., 2008), it has also framed academic attitudes according to the notion of a 'higher education governance' (Ferlie et al., 2008: 326).

These related trends of economisation, harmonisation and managerialisation of universities, higher education and research - here termed as academisation-has had considerable impacts on academic knowledge production. For example it has created a greater flexibility in appropriating funds and in more efficient allocation of resources, but simultaneously it has also generated greater difficulties in persevering long-term lines of research, as well as privileging mainstream research (Schimank, 2008). Facilitated by the Bologna Reform, the academisation of education and research and its standardisation is transforming knowledge production and education into globally marketable products. Subsequently as a result, the influence of interdisciplinary administrative bodies like university management, science policy organisations, research commissions and councils has increased (Fuchs \& Reuter, 2003; Masschelein \& Simons, 2012; Muche, 2005).

This externally imposed quest for academisation is further characterised by an increased research orientation in applied disciplines and the trend to frame research in measurable terms, such as the amount of third-party funding and peerreviewed publications (Felt \& Fochler, 2010). While scholarly regimentation and economisation of educational institutions has been described as particularly affecting knowledge production in the humanities and cultural studies (Bollenbeck \& Wende, 2007), this trend has had a significant impact on knowledge production in applied, skill-intense and artistic disciplines 
without identifiable and distinct research traditions such as architecture and the arts, whose applied and practice-based knowledge production processes are hardly compatible with the audit-oriented criteria of traditional research disciplines (Ammon \& Froschauer, 2013; Lesage \& Busch, 2007).

This article analyses the impact of such academisation trends on the discipline of architecture. It particularly focuses on the strains and boundaries that architectural faculties face in their research and teaching practice, where external disciplines are increasingly becoming involved due to the growing influence of administrative bodies and formalised practices such as evaluations, which have gained within these academisation trends. The analysis is guided by the assumption that architecture as an applied discipline is particularly concerned by such boundary work, and that these strains and demarcations frame and are framed by the specific character of architectural knowledge production-or the epistemic culture (Knorr Cetina, 1991) of architecture.

Based on ethnomethodological analyses of knowledge production in hard science disciplines such as molecular biology and high-energy physics in the context of STSdriven laboratory studies (Latour \& Woolgar, 1979; Traweek, 1988; Knorr Cetina, 1981), Knorr Cetina (1999) uses the term epistemic culture for the specific ways, contexts, arrangements and self-understandings in which knowledge is produced in certain disciplines and academic fields. Knorr Cetina (1999) defined her concept of epistemic cultures as consisting of an empirical (methodologies, theories and conceptualisations), an ontological (instruments, materials, processes and objects) and a social dimension (human interactions of context, environment and researchers in their specialised milieu with fellow workers). In her concept, epistemic cultures are specific ways of knowledge production or 'amalgams of arrangements and mechanisms', which in each specific field define the content of knowledge and how it is produced.

Based on the above-mentioned assumption that the boundary work emerging in the transformation of architecture into a research discipline is framed by the epistemic culture of architecture, this analysis implies a twofold approach:

\section{An analysis of the epistemic culture of architecture}

2. An investigation of the boundary work concerning architectural research

The epistemic culture of architecture has been analysed within a review of the available architectural, cultural studies and STS literature focusing on the specific character of architectural knowledge production. This analysis has used Knorr Cetina's (1999) analytical framework to identify the empirical, the ontological and the social dimension of the epistemic culture of architecture.

The boundary work in demarcating architectural knowledge production from science has been analysed with an empirical study. This study has investigated the implications of the European Bologna Reform on knowledge production in architecture with a particular focus on the teaching of design and design research in architecture. ${ }^{1}$ The data was collected at a Swiss architecture department. Methods consisted of qualitative interviews with faculty members, administrative staff and students, as well as participant observation at faculty meetings and within design studios. $^{2}$

The next section presents an analysis of selected architectural, cultural studies and STS literature describing architectural 
knowledge production. This analysis is carried out along the framework of epistemic culture (Knorr Cetina, 1991). Its focus is on the empirical, the ontological and the social dimension of the architectural knowledge production practice. The architectural and cultural studies literature tends rather to focus on questions regarding methods and theories rather than the working process itself, which includes the process of developing design ideas, the use of material objects or methodologies. These aspects have mainly been the focus of the STS-based ethnographies. Furthermore, the cultural studies contributions take a greater interest in architectural design (Mareis et al., 2010; Gethmann \& Hauser, 2009; Ammon \& Froschauer, 2013). The aim of the following section is to identify how the specific character of the epistemic culture of architecture has been described and will form the basis for the analysis presented in section 3 that addresses the fracturing borders emerging around architectural design research.

\section{The Epistemic Culture of Architecture}

In the context of professionalisation processes in the $19^{\text {th }}$ century, architecture was established as an academic discipline and transformed from an informal craft into a formal applied-science profession (Kostof, 1977). In the German-speaking world, architecture mainly became part of the engineering sciences at technical universities. Other institutional settings for training in architecture were art schools and universities and schools of architecture (Kostof, 1977). In its various pedagogical contexts, architecture went through periodic waves of scientisation such as during the design methods movement in the 1950s to 1970s and the digitisation of design in the 1990s (Scott Brown, 1999; Weckherlin, 2013). Since the late 1990s in the context of increased financial tightening at universities, the shift to 'new public management' of universities (Schimank, 2005) and the harmonisation of European higher education systems in the context of the Bologna Reform, the field of architecture has followed another trend towards academisation, marked by an expanded research orientation (e.g. Ammon \& Froschauer, 2013).

Even though education in architecture has had a longstanding research component because of its institutional establishment at universities, its traditional orientation was more that of a professional education than that of a science (Kostof, 1977). Due to the establishment of architecture at universities in a polytechnic context, a trend that occurred in most cases in Germany, Switzerland, but also in other national contexts, the applied aspects of a professional education have been at the forefront at those sites (Brain, 1991). Research in architecture has primarily been undertaken by neighbouring disciplines such as art history, sociology, social and human geography, material sciences and engineering statics, rather than by the discipline itself (Heintz et al., 2004). The field's lack of its own disciplinary research was mainly a phenomenon at technical universities in central Europe. This gap is known in architecture and the discourses on research by design can be seen as an attempt to fill it (Geiser, 2008). In the Anglophone community, where more beaux arts-oriented approaches located architecture in dedicated schools or art schools, an academic branch of architecture has been more established (Brain, 1991; Kostof, 1977). This lack of disciplinary research in architecture itself has significantly changed since the late 1990s, when applied disciplines underwent academisation and research activities were 
ramped up in those fields (e.g. Ammon \& Froschauer, 2013).

In the following section, Knorr Cetina's framework of epistemic cultures is applied to STS and cultural studies analyses of architecture. Sections will draw on the three specific empirical, ontological and social factors that frame the epistemic culture in this field.

\section{Empirical Dimension: Individual References Instead of Codified Theories}

The empirical dimension of architecture can be framed by an absence of codified theories and methods. Rather than to specified theories, architects typically refer to context devoid individual heuristics of the local and global built environment (e.g. Hauser, 2013). Such heuristics include: the 'form follows function' tenet; historic references to stylistic periods (Baroque, Byzantine, Post-modern, etc.); geographic or cultural areas (East Asia, Middle East, South Asia, Mediterranean, Scandinavian etc.); and varying building types (e.g. religious, institutional, single and multifamily residential, high rise, etc.), as well as contemporary heroic figures (e.g. Ludwig Mies van der Rohe, Frank Gehry, Zaha Hadid and Rem Koolhaas), who are described as playing the role that theories and research concepts do for traditional research disciplines (Yaneva, 2005, 2009; Henderson, 1999; Potthast, 1998). Hence, reference buildings and famous architects are used as sources of inspiration and are cited comparably to codified theories in academic writing of traditional research disciplines (Heintz et al., 2004).

Furthermore the individual, local, and user contexts are described as playing significant roles in the design process. Aerial, area, and neighbourhood photographs, street views, façade elevations, urban models, perspective renderings and the placement of the individual design solutions into a context of non-architectural elements are observed as being used for inspiration, as were façades and arranged post-card visualisations (Potthast, 1998; Houdart, 2008). In these terms, studio work and its inscriptions such as sketches, drawings and prototypes, rather than specific theories, methodologies and concepts are framed as the most important part of the architectural reference system (Henderson, 1999). The reason for the admission of a multiplicity of ideas in architecture is identified in architectural education, which is described as consisting of capacity-building in a number of basic categories, such as art, architectural history and theory, social sciences and environmental issues (Cuff, 1991: 63). Also, the main emphasis in the education of architects is on the practical education in the studio (Heintz et al., 2004), rather than on scholastic instruction. In architectural literature, this situational and context-related orientation is brought in relation to the specific architectural method, which is described as being mainly based on the example (Eberle \& Simmendinger, 2007).

Scholars of cultural studies, sociology and philosophy of science have drawn distinctions between scientific and architectural knowledge production, mostly based on the contrast of the two ideals of reproducibility versus singularity. That is, while artistic and architectural ideals have been characterised by concepts that include individuality, subjectivity and genius-loci, scientific ideals have been framed mainly by terms like objectivity, reproducibility and the 'search for truth' in a philosophy of science perspective (Heintz et al., 2004; Ammon, 2013; Weckherlin, 2013).

This analysis of the empirical dimension of architecture highlights the perception that there is a lack of a communitywide, shared pool of codified references. To sum up, in architecture, knowledge 
production is described as being oriented toward multidisciplinarity, individual situations and contexts. The epistemic culture of architecture is further described as following ideals like individuality, singularity and non-reproducibility and as being based on a variety of insights from different fields, such as the arts, art history, the social sciences and physics. While STS driven ethnographies mainly frame this individual approach as an absence of theoretical and methodological rigour, architectural literature identifies this approach as the architectural method.

\section{Ontological Dimension: Artistically Framed Knowledge Production Practices}

Most of the studies reviewed for this research have in relation to artistic disciplines described the ontological dimension of architectural knowledge production as rich in devices, instruments and materiality. In this conception, the design practice is framed as a nonlinear, volatile process of circulation, reformulation, back-andforth translation and re-adaptation. These studies have also described such work as consisting of handcraft, writing, material work, transition passages and intuitive factors of manipulating social spheres. They have further depicted architectural work as being framed by ideals such as individuality, singularity, a specific architectural gaze and a talent- and geniusoriented paradigm. Visual representations, as well as tools and objects such as pencil, paper and computers that are used to create sketches, drawings, plans and models have been characterised as being the core or the 'heart' of design work (Henderson, 1999), as the 'manifestations of knowledge' (Houdart, 2008) and as 'epistemic objects' (Ewenstein \& Whyte, 2009; Murphy, 2005; Ammon, 2010).

Further studies have tried to elaborate the specific character of design by focusing on practices, materials and genuine knowledge forms (e.g. Henderson, 1999; Houdart \& Chihiro, 2009; Hauser, 2013; Yaneva, 2005; Potthast, 1998). They have emphasised:

- handcraft such as drawing both by hand and computer-aided, colouring, gluing, layering, copying, pasting, constructing;

- text in the form of keywords, empirical references such as natural or historical documentation, forms and attributes from art history;

- tools such as paper, pen, pencil, ruler, goniometer, computer, paint, models;

- modelling materials such as wood, cardboard, clay, glass, Styrofoam, plastic;

- transitions in the form of translations, combinations and circular references between different working stages and dimensions such as 2D drawings and 3D models;

- and not least tacit aspects in the form of non-realised designs, rejected ideas, drawings, models, coatings, transformations, reproductions, interwoven processes.

Furthermore, the usage of drafting conventions such as line types, symbols, letters and notes to make designs compatible with others, has been observed in several ethnographies (Potthast, 1998; Henderson, 1999; Houdart \& Chihiro, 2009). The design practice is further described as repetitive processing, as re-adaptations, as digitisation, as copying, as cutting and pasting 2D and 3D designs, as back-andforth translations and as circulating ideas, 
as routine gestures, and as reiterative adjustments and skilful operations (Potthast, 1998; Yaneva, 2005). In particular, simultaneous thinking, imagining, drawing, and creation of artefacts and knowledge is described as specific for architectural design (Houdart, 2008; Ammon, 2010).

Further studies have pointed to the importance of visual aspects of the design process, such as concepts of an inner eye', a 'sensitive gaze' and the framing of architecture as a 'science of the eyes' (Heintz et al., 2004; Henderson, 1999; Daston \& Galison, 1992). Pictures and visualisations are framed as being core communication strategies in design processes. In particular, the specific ways of knowing, seeing and acting have been described as playing an important role, as well as the strong focus on intrinsic concepts such as 'creativity', 'productivity', 'threedimensional comprehension', 'drawing talent' and 'individual style' (Potthast, 1998; Luhmann et al., 1990; Stevens, 1990; Krasny \& Hausegger, 2008; Cuff, 1991: 121).

Several studies have drawn analogies between aesthetic and scientific practices. Based on the description of design as an experimental process of observing, testing, scaling and circulating plans, renderings and models those studies have identified a relation between design studio practices and practices in scientific laboratories (Yaneva, 2005, 2009). Furthermore, parallels have been drawn between the collective and iterative character of the design process on the one hand and scientific and technical practices on the other. Examples of these parallels are the heterogeneity of inscriptions and visualisations as well as the impossibility of ascribing the results to a simple intuition (Yaneva, 2005, 2009). In addition, architectural work has been described as being artistic, scientific and technical in parallel (Callon, 1996).
Hence, the ontological basis of the epistemic culture of architecture has been described as a particular orientation toward skills, handcraft and artistic practices; toward tacit knowledge forms; and toward flexible, intuition-based and non-linear working processes. Furthermore, this section points to a lack of vocabulary in STS literature for describing the ontological dimension of architectural knowledge production and instead has related to scientific laboratories practices, like 'testing, 'probing,' 'scaling' etc. In contrast, cultural studies analyses have put a stronger focus on identifying individual traits in architectural knowledge production regarding a specific gaze, translations, circulating knowledge and simultaneous thinking.

\section{Social Dimension: Enculturation Rites and Practice-Based Academic Reproduction}

The analysed literature stresses the importance of specific social and contextual aspects in the epistemic culture of architecture (Heintz et al., 2004; Potthast, 1998; Yaneva, 2005, 2009; Murphy, 2005). The social dimension in architectural knowledge production is framed as an integral aspect of disciplinary culture, in which qualification and collectivisation take place in unlimited working hours and in an absolute dedication to the profession. Formalised rites of collectivisation in the education and working practices of architects such as a highly intense, festive and sociable working culture and a 24-hour engagement have been described by several authors (Heintz et al., 2004; Cuff, 1991). In this conception, the identity of architects is seen as being framed by social factors such as a high degree of commitment, a certain amount of isolation from nongroup members, cohesion with the group, personal sacrifices, and rituals marking passages at various stages (Heintz et al., 
2004; Cuff, 1991). Furthermore, careers and tenure criteria have been described as being rather informal, as that is the tradition in the polytechnic model (Kostof, 1977), in which architectural professionalisation took place in Switzerland and elsewhere. Here, academic promotion is based on professional excellence rather than on academic qualification (Heintz et al., 2004). This means that design chairs are mostly appointed to practicing architects instead of academically tenured scholars.

To date Cuff (1991) has provided the most detailed description of the 'social dimension' of architectural knowledge production. In her analysis of the education of architects, she shows that schools of architecture play a crucial role in the socialisation process of professionals by promoting specific physical and social settings that provide not only education but also enculturation. In particular, most schools base their educational instruction on three highly socially framed rituals: the studio, the critique and the charrette (Cuff, 1991). The critique is framed as the main form of interaction between teachers and students in the studio; the exercises are established as hierarchically ritualised oneway discussions about design solutions given by the teacher and received by the students (Cuff, 1991). Also in the analyses of studio work, the practice of review and critique has been described as a core social factor in design processes. Critique takes place within the hierarchical structure of the office, led by a senior architect who does not design himself but rather comments on the drafts, and the junior architects who are designing (Potthast, 1998).

At the same time, collaborations on the same hierarchical level at the universities are described as being 'colloquial,' 'diligent' and 'bustling, in which everybody is in a state of permanent interaction and attentiveness (Heintz et al., 2004; Potthast, 1998; Yaneva,
2005, 2009; Murphy, 2005). Another specific social aspect of architectural knowledge production is the charrette, the final push before a project deadline. The charrette is described as both a highly competitive but also closely bonding situation, with a 24-hour-a-day, mixed working and party atmosphere, where students dedicate all their time to their projects. In designing they compete with each other, but in parallel give advice and help others where needed (Cuff, 1991).

Also, the design practice in the studios is framed as a highly discursive and interactive process of permanent exchange among team members and with external experts (Yaneva, 2009; Murphy, 2004). Often team analyses of models and plans are observed as taking place in informal settings combining meals and coffee breaks with discussion (Yaneva, 2009: 38). Collaborations between project partners, such as architects, engineers and other experts are also described as highly interactive events using plans and models as a kind of trading zone (Galison, 1997), in which experts from different fields exchange their knowledge (Yaneva, 2009: 158).

Within the social dimension, architecture has been described as a highly cohesive social community that produces its knowledge in a mixture of close collaboration and intense competition with peers. The community educates its members through ritualised 'passage points' such as charrettes and critique. The latter is established as a combination between a conference talk situation and 'peer review' (albeit neither anonymous nor formalised). Much of the training of architects takes place outside of academia within professional elite circles. Once established, a professional architect can return to academia.

This literature review has shown that particularly STS based literature that 
normally describes knowledge production in the hard sciences has difficulty in framing: 1) the individual, situational and context oriented; and 2) the tacit technical and aesthetic knowledge drawn from the epistemic culture of architecture. In particular, STS approaches so far lack a terminology to describe situational perspectives, tacit knowledge forms, and skill based epistemic practices like architectural design which differs from hard science knowledge production forms. In contrast architectural and cultural studies literature have put a stronger focus on the tacit forms of knowledge production and the ways architectural work could be theorised in terms of architectural methods and in what way design can be framed as research. This combined analysis has enabled a larger picture on how design and architectural knowledge production has been framed and already points to strains and boundaries in the academisation of architecture, which will be discussed in the next section.

\section{Strains and Boundaries in the Academisation of Architecture}

The analysis of the epistemic culture of architecture above captures the picture of an applied, skill-intense and highly cohesive social field that provides knowledge using individual theoretical and methodological approaches and which is rich in devices, instruments, artistic approaches and tacit practices. Based on participant observation and qualitative interviews conducted with professors, administrative staff and students at an architecture department in Switzerland, this section discusses strains and boundaries faced by architectural faculty members in their research and teaching practice due to the process of academisation. As it will be argued here, such boundaries mainly concern the situation that research structures are being built up in a discipline that lacks its own inherent and genuine research tradition - at least a tradition of research that is understood as such by other disciplines. In particular, such boundaries have been observed in threefold respects: They emerge within: 1) the architectural selfunderstanding of its epistemic practice as research; 2) the external perspective on architectural knowledge production by traditional research disciplines; and 3 ) the institutional processes, established in context of the economisation and harmonisation of higher education and research.

The analysed department, which is located at a technical university, is one of the largest in Switzerland with more than 30 professors and almost 2000 students. Traditionally, research and teaching were separated. While research is mainly conducted in neighbouring disciplines such as art history, sociology and engineering and led by professors recruited by academic promotion, design is taught as practicebased by faculty members who are employed from the pool of professional elites. This means that they mostly run their own architectural offices outside of their chair appointments at the university. In this system, the design studios are mainly taught by teaching assistants who are young professionals in the funding phase of establishing their own offices and who use their jobs at the department as a safe source of income. This clear distinction between research and teaching has become blurred in the context of academisation processes influenced by the Bologna Reform within the past 10 years. Design and construction chairs have become involved in academic research. Here, research was established out of a practice-based epistemic culture without its own distinct research tradition (Ammon \& Froschauer, 2013). This is also 
the case with the department analysed in our research.

The following sections discuss the observed boundaries emerging within the architectural self-understanding of its epistemic practice as research (3.1); those emerging within an external perspective on architectural knowledge production by traditional research disciplines (3.2); and those appearing within institutional processes established to economise and coordinate higher education and research (3.3).

\section{The Architectural Self-Understanding}

As this section will show, architects differ in their understanding of architectural epistemic practice as research. While some are convinced that even their work in the office qualifies as research, others question the academic status of architecture as such. Among the latter, a senior design professor at the department studied involves himself in boundary work by demarcating architecture from other traditional university's disciplines. The professor, who is a former dean of the department, is well known for his architectural practice. He leads a firm with 150 employees and 10 offices around the globe. In his opinion, architecture is misconceived as an academic field and the discussions over architectural research could have been avoided if architecture which in his view is a professional education and not an academic one - had not been established at traditional universities, where it is measured in terms of a research discipline:

Establishing architecture as an academic discipline at traditional universities emerged from a historic misunderstanding. (Professor 1, Swiss university architecture department, 17 April 2013, translated by the author)
A professor for building technologies is of another opinion. This professor has been a former dean of the department as well and leads a mainly local architecture office with 42 employees, in addition to holding his academic chair. In his view, architectural work qualifies as research, however as research that uses individual methodologies:

For me the discussion is a bit idle. Architects are definitely doing research. They have their own methodology. The only problem is that they are not using quantitative instruments. (Professor 2, Swiss university architecture department, 10 October 2013, translated by the author)

This quotation further shows that the lack of quantitative methods in architecture is seen as a problem. As the literature review, it also reveals the understanding of architects that their knowledge production is research and the framing of their own individual approaches as their specific research method. According to the interview partner, architectural research is practice-oriented and less interested in theory or methods. Subsequently, this professor sees the main reason for the lack of contributions in these areas is that the core interest of practicing architects who hold most of the design chairs at Swiss universities is practice and not primarily theory:

To build and to work in practice is our core interest. In very rare cases publications from architects are theoretical. What is the last relevant theoretical book of a practitioner? (Professor 2, Swiss university architecture department, 10 October 2013, translated by the author) 
As another quote from the same interview partner shows, the meaning and distinction of research and practice in architecture appears to be unclear, since practicing architects who hold design chairs are often convinced that the practice in their offices and its reflection contribute to research in their field:

Our research differs from traditional research fields, which is evident from our publications. It usually emerges from our practice; it reflects our office activities. (Professor 2, Swiss university architecture department, 10 October 2013, translated by the author)

As the literature review has shown, this is a widely shared notion in architecture. Due to this unclear distinction of research and practice, architects themselves are involved in boundary work and demarcate their own research from that of 'traditional' research fields. This is also the case within an external evaluation of the architecture department analysed in 2013 as commissioned by the head of the university. The assessment committee was composed of national and international faculty members in architecture, consisting of practitioners and academic architects. In its final report, the committee demarcated the epistemic culture of architecture from science and technology and classified it as multidisciplinary orientated, containing aspects of science, technology, social sciences and the arts. It further pointed to a lack of empirical orientation:

Architecture is neither science nor technology. It contains aspects of science and aspects of technology. It contains aspects of social sciences but is less empirical. Some facets of art are present. (Excerpt from an evaluation report of a Swiss architecture department, 10 January 2013)
The struggles of the committee in classifying architecture in terms of a discipline and the difficulties in recognising architectural knowledge production as research produce boundary work in the classification of architecture as having a multidisciplinary focus and a strong practice orientation. The professor for building technologies, the second interview partner here, has also mentioned the lack of empirical orientation where architectural knowledge production has not been based on theoretical coherence and methodological rigour. In his view it is based instead on a widely spread idea in architecture of creating something irreproducible and unique:

\begin{abstract}
Our University administration asks our department to subsume our research activities under a more traditional focus, as found in the research of art historians, the social scientists and the hard sciences. They all have clear rules and research in those fields is traditionally certified. We haven't cared so much about rules. What we are doing is not reproducible, normally it is unique. (Professor 2, Swiss university architecture department, 10 October 2013 , translated by the author)
\end{abstract}

Furthermore, the validity of design problems as research questions has not been clarified yet within the field, as shown by a growing literature focusing on the potential contents and paradigms of design research and research in design (Ewenstein \& Whyte, 2007; Geiser, 2008; Goldschmidt, 1991; Gerber et al., 2010; Weckherlin, 2013), as well as on the specific characteristics of design knowledge (Hauser et al., 2011; Hauser et al., 2013; Gethmann \& Hauser, 2009; Ammon, 2013). As the evaluation report shows, the committee has demarcated design research from a scientific research paradigm: 
As the definition of design research is discussed, [...] there is a threat that a strong technical orientation will lead to the misappropriation of a scientific paradigm for evaluation of research in design. (Excerpt from an evaluation report of a Swiss architecture department, 10 January 2013)

Therefore, the committee sees research in design threatened by the application of rigorous technical and sciencebased evaluation criteria. If such criteria are applied, architectural knowledge production becomes formally identifiable as research also by other disciplines. In this conception, genuine approaches in architecture such as design problems are not recognised as research by external disciplines and the university administration. This external perspective on architectural knowledge production is the topic of the next section.

\section{The External Perspective on Architectural Knowledge Production}

As this section will show, the applied and practice-based knowledge production in architecture is hardly compatible with audit criteria of traditional research disciplines. This has led to many challenges around the understanding of architectural knowledge production as research by neighbouring disciplines and granting architecture recognition as an academic field. A further topic for boundary work in evaluations and audits of architectural research by neighbouring fields is the unclear demarcation between research and practice in architecture. As the analysis in section 2.1 and recent cultural studies literature have shown, those strains in the recognition of architectural knowledge production as research particularly have concerned the theoretical, methodological and empirical basis of architectural knowledge production. Here, a controversial discussion of 'theory', 'methods', 'the empirical' quality of architectural work and specific architectural 'research', as well as associated concepts, has been brought to the fore (Krasny \& Hausegger, 2008; Hauser et al., 2011; Lorenz, 2004; Schoper, 2010; Ammon \& Froschauer, 2013). By discussing the case of a PhD student, this section illustrates boundary work performed by external disciplines in granting architectural knowledge production research status. ${ }^{3}$

In the analysed department academic staff increasingly pursues a doctorate and applies for third-party funding. ${ }^{4}$ This is also the case with a research and teaching assistant, whose research has been analysed within the mentioned project. He is a trained architect, who worked in practice after university and has now been working for several years at a construction chair. For two years he has been working on a practice based research project on a design problem, relevant to contemporary questions in construction. This student's PhD project cannot be assigned to any one of the classical research disciplines in the field of architecture, like art history, statics or materials sciences. Nor can it be related to any other discipline in the natural or engineering sciences.

In fall 2012 he tried to get his research plan approved by the research commission of his department. ${ }^{5}$ The commission, mainly composed of faculty members from traditional research disciplines in architecture, like art history and architecture theory, twice rejected the plan but then approved a slightly adapted third version. The commission based its original refusal on the argument that a historical perspective in the analysis is missing. 
The student also tried to get funding with a national research foundation, where the plan has also been rejected. The foundation's research commission, composed of members from the social sciences and the humanities, criticised missing hypotheses and references to current research in cultural studies, architectural theory and design theory, although both external peer reviewers did not mention this absence. Besides criticising some minor methodological details, one referee pointed out that it was difficult to assess the academic record of the research group because no peer-reviewed publications were listed. (Case collected in the analysis of a Swiss architecture department, 12 November 2013)

Such cases are not unique to architecture. They can emerge everywhere where peers from other disciplines have to evaluate external, inter- or transdisciplinary research. However in architecture as it is argued here, the demarcations not only concern the frictions borne out of conflicts with neighbouring and external disciplines involved in the evaluation of research. Rather as the interview and the evaluation report excerpts above have shown, the form and content of architectural research is inherently questioned and demarcated from scientific approaches. Furthermore, the eligibility of practicing architects to conduct academic research is debated. Conducting research projects and pursuing dissertations are new practices at design and construction chairs-at least in the country that is home to the department analysed. Without its own research tradition, hardly any architects are members of research commissions in universities and in research funding agencies and science foundations. Nor are there peers who are familiar with architectural research. Therefore, the boundaries for which this case illustrates are questions like who decides which projects can be funded, what research is eligible as a PhD project and in general; who defines what architectural research is and how it should look like.

Both the university's internal research commission, as well as the external research commission of the national research foundation criticised the lack of specific theoretical considerations. This shows that traditional research disciplines draw a boundary between the conceptual basis of the proposed research and that of an established research discipline regarding its theoretical considerations. The national research foundation's final decision was not based mainly on the external reviews - usually originating from within the applicant's community - but rather on the evaluation of the mainly interdisciplinary assessment commission. This points to the importance that external disciplines have in framing architectural research compared to internal peers in emerging research disciplines.

The criticism of missing hypotheses and references to current research in cultural studies, architectural theory and design theory points to another boundary that is drawn between architectural and 'real' research; namely again one of formalisation and references. This means that whether a proposed project is considered as fulfilling formal qualifications of 'research', will be accepted as a dissertation in a university department, or will receive funding, depends on whether members of assessment committees can assign the design of the proposed project to criteria that are used in established research disciplines. Furthermore, this case also stands for the consequences that emerge by the absence of a validated peer-review process. Hence, external disciplines are not 
able to integrate architectural publications into their criteria of measuring the quality of a publication. In this understanding, again the success of a proposed project mainly depends on the members of assessment committees and whether they can assign formalised scholarly quality criteria to the publications of the applicants.

\section{Institutional Processes}

This section will illustrate the boundaries emerging within the institutional processes established in context of the economisation and harmonisation of higher education and research such as tenure procedures, peer review and audit criteria. Concerning the process of tenure, architectural research practices have been demarcated from scientific ones with regard to a lack of standardised approaches. As mentioned in section 2.3, academic promotion is based on professional excellence rather than on academic qualification. As the evaluation committee states in the quotation below, the criteria for the eligibility of young academics for a chair are unclear, and formalised criteria in the form of dissertations and habilitations ${ }^{6}$ in tenure processes of design chairs are absent:

The definition of design research is to be discussed, both for the sake of current efforts within the department and for the purpose of clarifying tenure processes and expectations for junior faculty. (Evaluation report of a Swiss architecture department, 10 January 2013)

In addition to unclear tenure criteria, the evaluation committee also observed the lack of a standardised and validated peer review process. Again, the committee draws a boundary between a formalised understanding of a valid peer review and an informal one. In particular, the cooperative forms of knowledge production in architecture, combined with the ritualised and informal handling of critique during the education seem not to be intended to build up standardised forms of validation. The evaluation committee identified difficulties in the clarification of peer review criteria not only in design research, but also in all areas of research in the department:

It is important for the department to come to a clear understanding as to what constitutes valid peer review for design research (as well as other forms of research within the department, including historical, theoretical, and technical). (Excerpt from an evaluation report of a Swiss architecture department, 10 January 2013)

In particular, by observing the lack of specific criteria for measuring the qualification of design as research, the evaluation committee encourages the department analysed to develop specific criteria for architectural peer review in international cooperation with other architecture departments:

The central product is design. To assess the quality, productivity and relevance of this research the department is recommended to come up with specific criteria for peer review in an international league of architectural university colleges. (Excerpt from an evaluation report of a Swiss architecture department, 10 January 2013)

This quotation again reflects the externally imposed quest for auditable, evaluable and measurable research in the context of academisation processes. As the evaluation committee is aware of the difficulties of assessing architectural knowledge 
production within this context, it suggests that architecture should develop its own criteria for the appraisal of its research:

This potential problem suggests that discussions about design research need to involve leadership from the institution outside the department and even from other peer institutions. (Evaluation report of a Swiss architecture department, 10 January 2013)

To overcome these boundaries that have been established by the lack of a disciplinewide shared agreement on standards and criteria for the evaluation of design research, the evaluation committee sees a need to make universities and other peer institutions familiar with the specific knowledge production and research practices in architecture. The excerpts from the evaluation report have shown that the specific character of architectural knowledge production leads to a lack of understanding of architectural research on the institutional level of the university administration and therefore to a demarcation of architectural knowledge production from academic research. To cope with this misunderstanding, the evaluation committee sees a need for international coordination in developing evaluation criteria for tenure processes and peer review criteria for architectural research also in an international cooperation.

\section{Research in Architecture as a Matter of Interdisciplinary Boundary Work}

The aim of this analysis was to investigate the restrictions and resulting conflicts that the introduction of academisation processes generate within the multifaceted contexts and arrangements by which knowledge is produced in architecture. To achieve this goal, it was based on two STS concepts: The concept of 'epistemic culture' (Knorr Cetina, 1999) and that of boundary work (Gieryn, 1983). The first concept has enabled a threedimensional analysis of the empirical, the ontological and the social dimensions of the specific ways knowledge is produced in the field of architecture and the ways in which this field understands its research, as well as itself as an academic discipline. This multidimensional approach has emerged as helpful in analysing the multi-faceted aspects in which academic knowledge is produced. Additionally, this research into architectural knowledge production in the context of academisation has also unearthed one of the weaknesses in this concept. That is, namely the exclusion of the institutional dimension (Cutcliffe, 2001). As this study has shown, the institutional context and its specific embodiment have an important impact on the way knowledge is produced. In this respect, the boundary work concept was helpful, as it has enabled the theorisation of the struggles faculty members face in the academisation of architectural knowledge production by articulating the field's self understanding from internal perspectives, as well as how it is viewed from external institutional processes.

Recent literature in STS has described externally imposed trends to establish new public management structures in universities, as well as the economisation and harmonisation of higher education systems. These trends have led to a quest for academisation in practice-oriented disciplines. This analysis contributes an empirical case that sheds light on the consequences of such academisation processes on the epistemic culture of architecture, which might also be true for other practice-based disciplines. As section 
1 has shown, the trend of academisation leads to an increased influence of administrative bodies and formalised practices such as auditing, evaluating, measuring and standardising research and teaching structures in academic disciplines. In section 2 , architecture has been described as an applied, skill-intense and socially highly cohesive epistemic culture whose knowledge is rich in devices, instruments, artistic approaches and tacit practices. This has produced a gap between a rich use of devices, instruments and artistic approaches in the design process and 'theory' that is mainly produced in neighbouring disciplines such as art history and sociology.

The empirical material discussed in section 3 , has pointed to three areas of boundary conflicts emerging in the academisation of architecture: 1) the architectural self-understanding of its epistemic practice as research; 2) the external perspective on architectural knowledge production by traditional research disciplines; and 3) within the institutional processes established to economise and harmonise higher education and research. In general, the quotations from the interviews and the evaluation report point to the assumption that most of the mentioned boundary work has emerged in the context of a disciplinary transition. Architecture as a discipline appears to be in a transitional phase from a practice based education without its own inherent and genuine research tradition to that of a research discipline. In this transition phase, scholars increasingly start to conduct research in an instable situation where research structures are unclear and the disciplinary development is not yet finalised (Stichweh, 1993; Böhme et al., 1974).

In core areas, such as design and construction research, approaches that are understood as research by other disciplines are not yet established. In this context, the research status of knowledge produced in this field and the eligibility to frame a design problem as a research question are subject of boundary work and demarcations of architecture from science. The demarcation of architecture from science is further drawn along formal issues like research methods, theories, the separation of theory and practice, as well as along the formalisation of tenure and peer review criteria. Further boundaries emerge around the highly cohesive social environment that puts a strong focus on individual talent instead of standardised and validated approaches for tenure and peer-review processes.

The increased influence of academisation processes produces particular difficulties for architecture, since due to its limited research tradition has little representation in research commissions and councils. Those commissions, often composed of members of traditional research disciplines with a restricted understanding of architectural knowledge production, acquire a high significance in the framing of the form and the content of research in architecture. This is the case as they decide whether architectural research projects can be funded and whether a design or a constructional problem is eligible as a research project. Hence, the meaning of research in applied, skill-intense disciplines such as architecture has become a matter of negotiation, involving not only the field itself, but also traditional research disciplines and interdisciplinary and administrative bodies such as research commissions and councils.

As the excerpts from the evaluation report in section 3 have further shown, such negotiations might result in applying rigorous technical and science-based evaluation criteria on architectural knowledge production. As a consequence, knowledge production in architecture becomes formally identifiable as research within traditional academic disciplines 
but in parallel might lose its specific character such as its skill-orientation, its tacit knowledge forms, and therefore its strong link with the design process and the architectural practice.

\section{Acknowledgements}

I would like to thank the Swiss National Science Foundation (SNF) and the ETH Zurich Department of Architecture for supporting this research; Ignaz Strebel; Krishna Bharathi and two anonymous reviewers for their helpful comments and their support.

\section{References}

Ammon S (2010) Transforming Tacit Knowledge: The Example of Architectural Drawings. In: Professur Theorie und Geschichte der modernen Architektur (eds) Architecture in the Age of Empire/Die Architektur der neuen Weltordnung. $11^{\text {th }}$ International Bauhaus Colloquium. Weimar: Verlag der Bauhausuniversität Weimar, 598-609.

Ammon S (2013) Wie Architektur entsteht. Entwerfen als epistemische Praxis. In: Ammon S \& Froschauer EM (eds) Wissenschaft Entwerfen. München: Wilhelm Fink, 337-362.

Ammon S \& Froschauer EM (2013) Wissenschaft Entwerfen. München: Wilhelm Fink.

Böhme G, van den Daele W \& Krohn W (1974)

Die Finalisierung der Wissenschaft. In: Diedrich W (ed) Theorien der Wissenschaftsgeschichte. Beiträge zur diachronen Wissenschaftstheorie. Frankfurt am Main: Suhrkamp, 276-311.

Bollenbeck G \& Wende W (2007) Der Bologna-Prozess und die Veränderung der Hochschullandschaft. Heidelberg: Synchron.

Brain D (1991) Practical Knowledge and Occupational Control: The
Professionalization of Architecture in the United States. Sociological Forum 6(2): 239-268.

Braun D \& Merrien F-X (1999) Towards a New Model of Governance for Universities? A Comparative View. London: Kingsley.

Callon M (1996) Le travail de la conception en architecture. Situations Les Cahiers de la recherche architecturale 37(1er trimestre): 25-35.

Cuff D (1991) Architecture: The Story of Practice. Cambridge MA: MIT Press.

Cutcliffe S (2001) Reviewed Work: Epistemic Cultures: How the Sciences Make Knowledge by Karin Knorr Cetina. Science, Technology, \& Human Values 26(3): 390-393.

Daston L \& Galison P (1992) The Image of Objectivity. Representations 40(Autumn 1992): 81-128.

Denzin N \& Lincoln Y (2000) Handbook of Qualitative Research. London: Sage.

Eberle D \& Simmendinger P (2007) Von der Stadt zum Haus: Eine Entwurfslehre - From City to House A Design Theory. Zürich: GTA Verlag.

Ewenstein B \& Whyte JK (2007) Beyond Words: Aesthetic Knowledge and Knowing. Organization Studies 28(5): 689-708.

Ewenstein B \& Whyte JK. (2009) Knowledge Practices in Design: The Role of Visual Representations as 'Epistemic Objects'. Organization Studies 30(1): 07-30.

Felt U \& Fochler M (2010) Riskante Verwicklungen des Epistemischen, Strukturellen und Biographischen: Governance-Strukturen und deren mikropolitische Implikationen für das akademische Leben. In: Biegelbauer P (ed) Steuerung von Wissenschaft? Die Governance des österreichischen Innovationssystems. Innovationsmuster in der österreichischen Wirtschaftsgeschichte. Innsbruck: Studienverlag, 297-327. 
Ferlie E, Musselin C \& Andresani G (2008) The Steering of Higher Education Systems: a Public Management Perspective. Higher Education 56(3): 325-348.

Fuchs H-W \& Reuter LR (2003) Internationalisierung der Hochschulsysteme: Der Bologna-Prozess und das Hochschulwesen der USA. Hamburg: Universität der Bundeswehr.

Galison P (1997) Image \& Logic: A Material Culture of Microphysics. Chicago: The University of Chicago Press.

Geiser R (2008) Explorations in Architecture: Teaching Design Research. Basel: Birkhäuser.

Gerber A, Unruh T \& Geissbühler D (2010) Forschende Architektur. Luzern: Quart Verlag.

Gethmann D \& Hauser S (2009) Kulturtechnik Entwerfen: Praktiken, Konzepte und Medien in Architektur und Design Science. Bielefeld: transcript.

Gieryn T (1983) Boundary-Work and the Demarcation of Science from Non-Science: Strains and Interests in Professional Ideologies of Scientists. American Sociological Review 48(6): 781-795.

Gieryn T (1999) Cultural Boundaries of Science. Chicago: University of Cicago Press.

Gisler P \& Kurath M (2015) Réconfiguration de la comprehension des disciplines en architecture, design et arts visuels. In: Gorga A \& Leresche J-P (eds) Transformations des disciplines adadémiques. Paris: Editions des archives contemporaines, 165-179.

Goldschmidt G (1991) The Dialectics of Sketching. Creativity Research Journal 4(2): 123-143.
Hauser S (2013) Verfahren des Überschreitens. Entwerfen als Kulturtechnik. In: Ammon S \& Froschauer EM (eds) Wissenschaft Entwerfen. München: Wilhelm Fink, 363-383.

Hauser S, Kamleithner C \& Meyer R (2011) Architekturwissen. Grundlagentexte aus den Kulturwissenschaften - Zur Ästhetik des sozialen Raumes. Bielefeld: transcript.

Hauser S, Kamleithner C \& Meyer R (2013) Architekturwissen. Grundlagentexte aus den Kulturwissenschaften - Zur Logistik des sozialen Raumes. Bielefeld: transcript.

Heintz B, Merz M \& Schumacher C (2004) Wissenschaft, die Grenzen schafft: Geschlechterkonstellationen im disziplinären Vergleich. Bielefeld: transcript.

Henderson K (1999) On Line and On Paper: Visual Representations, Visual Culture, and Computer Graphics in Design Engineering. Cambridge MA: MIT Press. Houdart S (2008) Copying, Cutting and Pasting Social Spheres: Computer Designers' Participation in Architectural Projects. Science Studies 21(1): 47-63.

Houdart S \& Chihiro M (2009) Kuma Kengo: An Unconventional Monograph. Paris: éditions donner lieu.

Knorr Cetina K (1981) The Manufacture of Knowledge: An Essay on the Constructivist and Contextual Nature of Science. Oxford: Pergamon Press.

Knorr Cetina K (1991) Epistemic Cultures: Forms of Reason in Science. History of Political Economy 23(1): 105-122.

Knorr Cetina K (1999) Epistemic Cultures: How the Sciences Make Knowledge. Cambridge MA: Harvard University Press.

Kostof S (1977) The Architect: Chapters in the History of the Profession. Oxford: University Press. 
Krasny E \& Hausegger G (2008) Architektur beginnt im Kopf: The Making of Architecture. Basel: Birkhäuser.

Latour B \& Woolgar S (1979) Laboratory Life: The Construction of Scientific Facts. Beverly Hills: Sage.

Lesage D \& Busch K (2007) A Portrait of the Artist as a Researcher. The Academy and the Bologna Process. Antwerpen: MuHKA.

Lorenz P (2004) Entwerfen: 25 Architekten - 25 Standpunkte. München: Deutsche Verlags-Anstalt.

Luhmann N, Vunsen FD \& Baecker D (1990) Unbeobachtbare Welt: Über Kunst und Architektur. Bielefeld: Haux.

Maasen S \& Weingart P (2006) Unternehmerische Universität und neue Wissenschaftskultur. In: Krücken G (ed) Universitäre Forschung im Wandel. Themenheft: Die Hochschule 15, 19-45.

Maesse J (2010) Die vielen Stimmen des Bologna-Prozesses: Zur diskursiven Logik eines bildungspolitischen Programms. Bielefeld: transcript.

Mareis C, Joost G \& Kimpel K (2010) Entwerfen - Wissen - Produzieren: Designforschung im Anwendungskontext. Bielefeld: transcript.

Masschelein J \& Simons M (2012) Globale Immunität oder eine kleine Kartographie des europäischen Bildungsraums. Zürich: Diaphanes.

Muche F (2005) Opening up to the Wider World: The External Dimension of the Bologna Process. Bonn: Lemmens.

Murphy KM (2004) Imagination as Joint Activity: The Case of Architectural Interaction. Mind, Culture, And Activity 11(4): 267-278.

Murphy KM (2005) Collaborative Imagining: The Interactive Use of Gestures, Talk, and Graphic Representation in Architectural Practice. Semiotica 156-1(4): 113-145.
Potthast J (1998) 'Sollen wir mal ein Hochhaus bauen?' Das Architekturbüro als Labor der Stadt. WZB-disscussion paper. Berlin: Wissenschaftszentrum.

Schimank U (2005) 'New Public Management' and the Academic Profession: Reflections on the German Situation. Minerva 43(1): 361-376.

Schimank U (2008) Ökonomisierung der Hochschulen - eine MakroMeso-Mikro-Perspektive. In: Rehberg K-S (ed) Die Natur der Gesellschaft. Verhandlungen des 33. Kongresses der DGS in Kassel 2006. Frankfurt, New York: Campus, 622-635.

Schoper P (2010) Zur Identität von Architektur: Vier zentrale Konzeptionen architektonischer Gestaltung. Bielefeld: transcript.

Schultheis F, Cousin P-F and Roca Escoda M (2008) Humboldts Albtraum. Der Bologna-Prozess und seine Folgen. Konstanz: UVK Verlagsgesellschaft $\mathrm{mbH}$.

Scott Brown D (1999) The Hounding of the Snark. In: Galison P and Thompson E (eds) The Architecture of Science. Cambridge MA: MIT Press, 375-384.

Stevens G (1990) The Favored Circle: The Social Foundations of Architectural Distinction. Cambridge MA: MIT Press.

Stichweh R (1993) Wissenschaft Universität Professionen: Soziologische Analysen. Frankfurt am Main: Suhrkamp.

Traweek S (1988) Beamtimes and Lifetimes: The World of High-Energy Physicists. Cambridge MA: Harvard University Press.

Weckherlin G (2013) Vom Betriebscharakter des Entwerfens. Konjunkturen der Verwissenschaftlichung in der Architektur. In: Ammon S and Froschauer EM (eds) Wissenschaft Entwerfen. München: Wilhelm Fink, 171-204. 
Weingart P (2001) Die Stunde der Wahrheit? Vom Verhältnis der Wissenschaft zu Politik, Wirtschaft und Medien in der Wissensgesellschaft. Weilerswist: Velbrück Wissenschaft.

Yaneva A (2005) Scaling Up and Down: Extraction Trials in Architectural Design. Social Studies of Science 35(6): 867-894.

Yaneva A (2009) The Making of a Building: A Pragmatist Approach to Architecture. Bern: Peter Lang.

\section{Notes}

1 This project is part of a larger research project that analyses the impact of the European Bologna Reform on the education of aesthetic practices in Swiss architecture, design and fine arts departments (Funded by SNF; grant number 143206).

2 These data were collected at a Swiss architecture department between fall 2012 and spring 2014. Methods consisted of continued participant observations at faculty meetings and long-time participant observation in the bachelor's and some master's design studios and of qualitative interviews. Those interviews were conducted with faculty members, department representatives for research and teaching, and doctoral students. Furthermore, the content of current research projects and dissertations was analysed. The observations were recorded in research protocols, the interviews were transcribed and these documents were analysed, using the method of content analysis (Denzin \& Lincoln, 2000).

3 A short version of this case has been discussed in Gisler \& Kurath (2015).

4 As an example, at the department analysed the number of architectural dissertations (PhDs) in 2012 was more than twice as high as in 2000 (see: http:/e-collection.library.ethz.ch/list/ subject? parent_id=465586/, accessed 16.01.2013).

5 All PhD students of the department need to get approval of their projects by the commission before they start their second year of research.

6 This references the German and Swiss system, in which academics are required to write a second thesis - the habilitation thesis - after their PhD to become eligible as a professor.

Monika Kurath

ETH Zurich, Department of Architecture Centre for Research on Architecture, Society \& the Built Environment

Stefano-Franscini-Platz 5

CH-8093 Zurich, Switzerland

email:kurath@arch.ethz.ch 